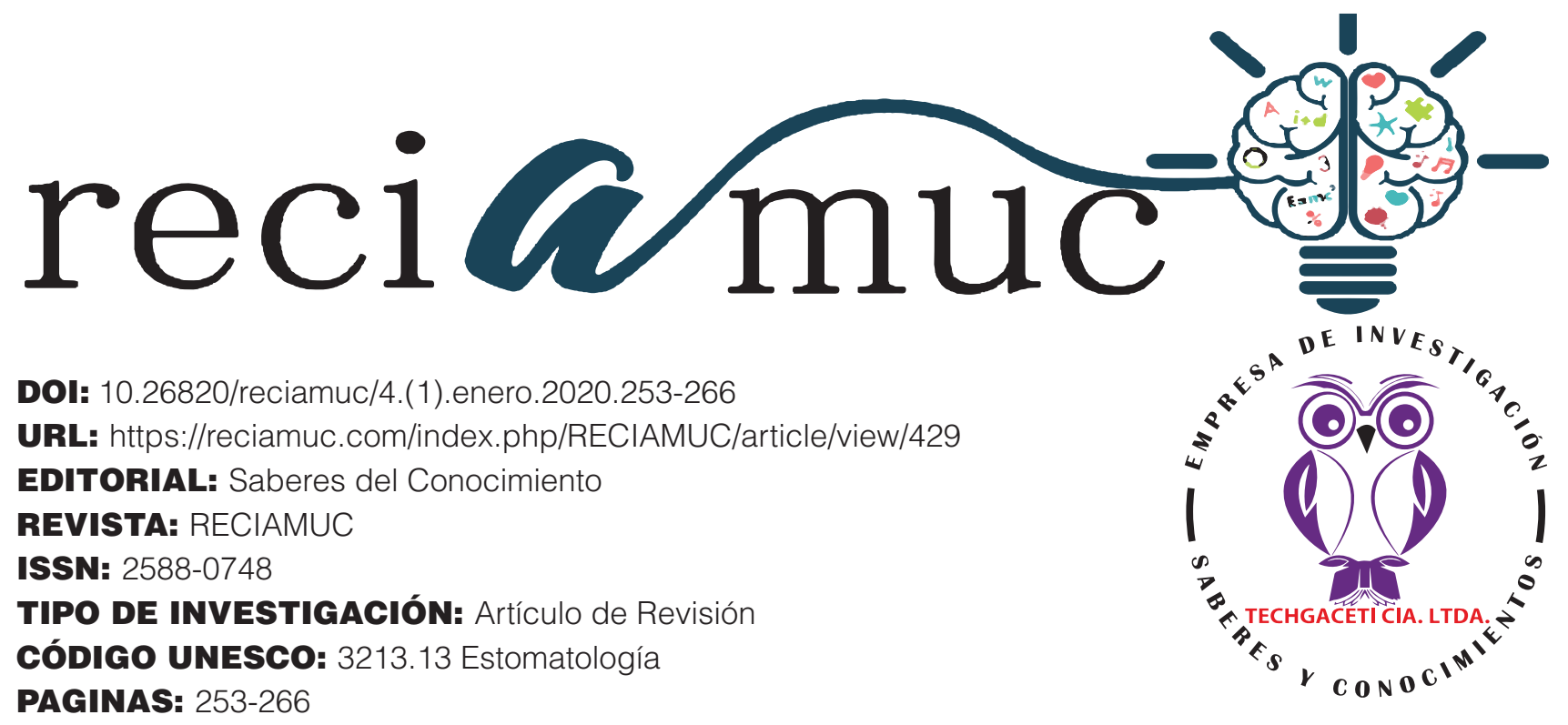

\title{
Obturación del sistema de conductos radiculares. Una revisión de la literatura
}

\author{
Root canal system filling. \\ A review of the literature
}

Enchimento do sistema de canais radiculares.
Uma revisão da literatura

María Jacqueline Cedeño Delgado'; Patricia Judith Pinos Robalino2; Patricia Ivonne Segovia Palma³

RECIBIDO: 18/11/2019 ACEPTADO: 20/12/2019 PUBLICADO: 31/01/2020

1. Magister en docencia Univesitaria e Investigación Educativa; Doctora en Odontología; Universidad de Guayaquil; Guayaquil, Ecuador; maria.cedenod@ug.edu.ec; (D) https://orcid.org/0000-0002-9865-0938

2. Magister en Diseño Curricular; Doctora en Odontología; Universidad de Guayaquil; Guayaquil, Ecuador; patricia.pinosr@ug.edu.ec; (D) https://orcid.org/0000-0001-7170-9381

3. Magister en Diseño Curricular; Doctora en Odontología; Universidad de Guayaquil; Guayaquil, Ecuador; patricia.segoviap@ug.edu.ec; (D) https://orcid.org/0000-0003-2551-8036

CORRESPONDENCIA

Eva María de Lourdes Loaiza Massuh

eva.loaizam@ug.edu.ec

Guayaquil, Ecuador 


\section{RESUMEN}

Cuando se realiza una terapia endodóntica, no es nada sencillo ejecutar la obturación de conductos radiculares por vía ortógrada, es por ello que alcanzar el éxito en este tipo de intervenciones pudiera depender en gran medida del vasto conocimiento de la raíz y de la morfología del sistema de conductos radiculares, lo que a su vez implica, que el especialista este siempre atento a las posibles variaciones y complicaciones que se pueden presentar, debido a que cualquier traza de conducto no tratado puede derivar en un penoso fracaso del tratamiento. Con el propósito de revisar la literatura cientificoacadémica reciente, disponible de manera completa y libre con respecto a la temática planteada, y a la vez, de presentar los resultados de dicho proceso como evidencia, se estima referir aquellas fuentes representativas que en síntesis favorezcan la materialización de un contenido nuevo. Los resultados obtenidos alcanzaron para satisfacer el objetivo previamente establecido, ya que con estos se logró exponer sobre algunas acepciones respecto a la obturación del sistema de conductos radiculares, así como también sobre su anatomía, preparación previa a la obturación, y sobre algunos de los materiales y técnicas empleadas en este tipo de intervenciones. Se concluye destacando la responsabilidad del especialista tratante en cuanto a su ardua preparación para abordar este tipo de intervenciones tan delicadas, todo esto en aras de procurar en todo momento de llevar a cabo un procedimiento seguro e idóneo para cada caso en particular. Así mismo, se ha resaltado que la literatura ha dejado ver que el examen radiográfico representa un tenue valor sugerente, en las interpretaciones endodónticas. Igualmente se ha referido que de la técnica de obturación y del cemento utilizado dependerá la tridimensionalidad del selle apical, aspectos estos que terminan siendo determinantes a la hora de minimizar el paso de bacterias hacia el periápice. En definitiva, la clave del éxito de la obturación del sistema de conductos radiculares radicará en la preparación de estos, que en líneas generales incluye un adecuado procedimiento de instrumentación, irrigación y medicación.

Palabras clave: Ortógrada, Morfología del Sistema, Variaciones, Tridimensionalidad del Selle Apical, Periápice.

\section{ABSTRACT}

When an endodontic therapy is performed, it is not easy to execute the root canal filling by orthograde route, which is why achieving success in this type of interventions could depend largely on the vast knowledge of the root and the morphology of the system of root canals, which in turn implies that the specialist is always attentive to the possible variations and complications that may occur, because any trace of untreated duct can result in a painful treatment failure. With the purpose of reviewing the recent scientific-academic literature, available in a complete and free manner with respect to the proposed theme, and at the same time, presenting the results of said process as evidence, it is estimated to refer those representative sources that in synthesis favor the materialization of New content The results obtained were achieved to meet the previously established objective, since with these it was possible to present some meanings regarding the filling of the root canal system, as well as its anatomy, preparation prior to filling, and some of the materials and techniques used in this type of interventions. It concludes by highlighting the responsibility of the treating specialist in terms of his arduous preparation to address such delicate interventions, all this in order to try at all times to carry out a safe and suitable procedure for each particular case. Likewise, it has been highlighted that the literature has shown that the radiographic examination represents a tenuous suggestive value, in endodontic interpretations. Likewise, it has been mentioned that the three-dimensionality of the apical seal will depend on the sealing technique and the cement used, aspects that end up being decisive in minimizing the passage of bacteria towards the periapice. In short, the key to the successful sealing of the root canal system will be the preparation of these, which generally includes an adequate procedure for instrumentation, irrigation and medication.

Keywords: Orthógrada, System Morphology, Variations, Three-dimensionality of the Apical Selle, Periápice.

\section{RESUMO}

Quando uma terapia endodôntica é realizada, não é fácil executar o preenchimento do canal radicular por via ortógrada, razão pela qual o sucesso nesse tipo de intervenções pode depender em grande parte do vasto conhecimento da raiz e da morfologia do sistema de canais radiculares. , o que implica que o especialista esteja sempre atento às possíveis variações e complicações que possam ocorrer, pois qualquer vestígio de duto não tratado pode resultar em uma falha dolorosa do tratamento. Com o objetivo de revisar a literatura científico-acadêmica recente, disponível de forma completa e gratuita com relação ao tema proposto e, ao mesmo tempo, apresentar os resultados desse processo como evidência, estima-se que se refira as fontes representativas que em síntese, favorecer a materialização de novos conteúdos. Os resultados obtidos foram alcançados para atender ao objetivo previamente estabelecido, pois com estes foi possível apresentar alguns significados quanto ao preenchimento do sistema de canais radiculares, bem como sua anatomia, preparação antes do preenchimento, e alguns dos materiais e técnicas utilizados neste tipo de intervenções. Conclui destacando a responsabilidade do especialista em tratamento em termos de sua árdua preparação para abordar intervenções tão delicadas, tudo isso para tentar sempre executar um procedimento seguro e adequado para cada caso em particular. Da mesma forma, destacou-se que a literatura mostra que o exame radiográfico representa um valor sugestivo tênue, nas interpretações endodônticas. Da mesma forma, foi mencionado que a tridimensionalidade do selo apical dependerá da técnica de selagem e do cimento utilizado, aspectos que acabam sendo decisivos para minimizar a passagem de bactérias em direção ao periapice. Em suma, a chave para o sucesso do selamento do sistema de canais radiculares será a preparação destes, que geralmente inclui um procedimento adequado para instrumentação, irrigação e medicação.

Palavras-chave: Ortógrada, Morfologia do Sistema, Variações, Tridimensionalidade do Selo Apical, Periápice. 


\section{Introducción}

Durante las últimas décadas, la endodoncia se ha beneficiado de los innumerables avances y recursos tecnológicos con el objetivo de mejorar el pronóstico del tratamiento de conductos radiculares, contribuyendo así a la preservación de los dientes. (Bejarano, 2014)

Vieira (2014) expone que "La obturación de los conductos radiculares forma parte del proceso endodóncico, y constituye la última etapa del tratamiento de dichos conductos". En detalle, de este experto puede igualmente deducirse que esta técnica se trata de un cierre de los conductos radiculares normales e irregulares de la forma más herméticamente posible, con cierta clase material sellante que sea suficientemente soportado por el tejido conectivo del periápice.

Apoyados en el criterio de la Asociación Americana de Endodoncia (AAE, por sus siglas en inglés), Giudice \& Torres (2011) han referido que la obturación del sistema de conductos radiculares es idónea teniendo en consideración las siguientes características:

- Debe ser realizada de forma tridimensional para lograr prevenir la percolación y microfiltración hacia los tejidos periapicales del contenido del sistema de conducto radicular y también en sentido contrario.

- Utilizar la mínima cantidad de cemento sellador, el cual debe ser biológicamente compatible al igual que el material de relleno sólido, y químicamente entre sí para establecer una unión de los mismos y así un selle adecuado.

- Radiográficamente el relleno debe extenderse lo más cerca posible de la unión cemento dentinal y observarse denso. El conducto obturado debe reflejar una conformación que se aproxime a la morfología radicular. Así mismo, debe mostrar una preparación continua en forma de embudo y estrecha en el ápice, sin excesiva eliminación de estructura dentinaria en cualquier nivel del sistema del conducto, porque el material obturador no fortalece la raíz ni compensa la pérdida de dentina.

- Es por esto la importancia de los diversos sistemas de obturación que aparecen y cumplan estas características para el éxito de nuestro tratamiento de conductos radiculares. (pág. 166)

Toledo, Alfonso, \& Barreto (2016) apoyados en sus fuentes han dicen que:

En los últimos 25 años, se ha incrementado de forma notaria el número de dientes que han

recibido tratamiento endodóntico. El interés de los pacientes por conservar sus dientes también ha aumentado de modo notable, por lo que un fracaso endodóntico no significa una extracción del diente, sino, con frecuencia, el deseo de conservarlo. (pág. 207)

Paralelamente, Mejía \& Bustos afirman que, cuando se realiza una terapia endodóntica, no es nada sencillo ejecutar la obturación de conductos radiculares por vía ortógrada, en razón de

la complejidad anatómica que representan las dimensiones de los conductos radiculares internamente, las limitaciones que encontramos en cuanto a acceso y los cambios que producen en la anatomía del conducto durante la instrumentación que pueden llevar a accidentes como transportación de foramen, perforaciones y escalones. (2012, págs. 392-393)

Reiterando la obra de Toledo et al. (2016), se considera importante mencionar que estos, en base a sus fuentes, refirieron que les fue posible identificar una mayor frecuencia de personas con edades comprendidas entre los 36 a 45 años (32.1\%) que necesitan tratamiento endodóntico, sin embargo, tras

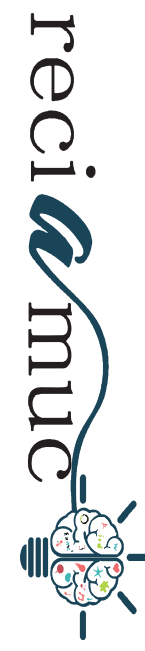


sus propios ensayos, lograron identificar que en relación con a las necesidades de tratamiento endodóntico, fueron los pacientes con edades comprendidas entre 35 y 59 años quienes constituyeron el grupo más representativo. De la misma manera, constataron que este grupo de pacientes fueron "los más afectados por lesiones pulpares y periapicales, por el mayor tiempo de exposición a factores intrínsecos y extrínsecos que laceran la estabilidad del sistema estomatognático". Adicionalmente indicaron que, otros datos que obtuvieron fueron los que coincidieron con los resultados expresados por Gaviria y por Pineda, respectivamente, puesto que, en relación al sexo, los tres estudios resultaron dejar en evidencia un marcado proclive que las mujeres representan en relación a un número mayor de casos de lesiones pulpares y afecciones endodónticas.

Este desarrollo investigativo se ha limitado a la exposición que otros tratadistas refieren con respecto a la obturación del sistema de contuctos radiculares, con la finalidad de construir un material de apoyo que no solamente sirva de al estudiante o profesional en la materia, sino también represente un aporte a cualquier lector interesado en este tipo de recurso bibliográfico. En base a ello, a continuación, se procede a exponer algunos conceptos fundamentales en relación a la obturación de conductos radiculares, así como también sobre su anatomía, preparación previa a la obturación, y sobre algunos de los materiales y técnicas empleadas en este tipo de intervenciones.

\section{Materiales y Métodos}

El objeto de la presente investigación se delimita a una revisión de literatura cientificoacadémica, que se halle disponible mediante múltiples consultas a diferentes bases de datos, destacándose entre estas la de: PubMed, SciELO, MedlinePlus, NCBI, Mediagraphic, y otras. En base a ello, fue indispensable disponer de computadoras personales con conexión a internet como recurso material.

La revisión se efectúa a principios de enero del corriente, y también incluyó búsquedas en portales web de varias asociaciones y fundaciones nacionales, regionales e internacionales, desarrolladas tanto en español como en inglés, y enfocadas, preferiblemente, en el área de la odontología y endodoncia. Sin embargo, fueron igualmente considerados los resultados obtenidos de otros proveedores de literatura cientificoacadémica en área de medicina y salud. En todos los casos se utilizaron las expresiones "conductos radiculares", "sistema de conductos radiculares" y "Obturación del sistema de conductos radiculares" como descriptores de búsqueda, mientras que criterios de idioma español e inglés y publicaciones hechas en los últimos diez años, definieron las otras dos variables que, a grandes rasgos, constituyeron una primera fase de selección.

En general, todo el contenido analizado corresponde a distintos tipos artículos científicos (con y sin metadatos) encontrados en revistas de categoría científica, así como también otros tipos de materiales bibliográficos producidos o promovidos por entes, instituciones, organizaciones, sociedades o asociaciones de carácter público o privado, sean nacionales, internacionales o multilaterales; de procedencia Americana o Europea, e inclusive, de cualquier otra región de habla hispana o anglosajona, preferiblemente; que proveyeran de manera completa y gratuita el acceso a libros digitalizados o electrónicos, recursos en formato electrónico o digital de cualquier tipo, archivos o contenidos alusivos a protocolos, consensos, manuales, guías clínicas, boletines informativos, ensayos, tesis de grado, posgrado o doctorado, informes, proyectos y demás documentos.

Seguidamente, entre los propios integrantes de este equipo se comparte y distribuye el compendio del material bibliográfico preseleccionado, para seguidamente llevar 
a cabo la lectura exhaustiva de cada uno de ellos, a fines de discutirlos.

Cabe destacar que, fue inevitable proceder a depurar el cúmulo de resultados obtenidos, por lo que, de manera progresiva, se fueron aplicando otros criterios de selección tales como: acceso completo y gratuito, idioma español e inglés, área de odontología, endodoncia, salud dental-bucal, medicina, seres humanos; entre otras discreciones inherentes a la especificidad del tema en cuestión. De allí es que, mediante un consensuado discernimiento, se conserva todo el contenido considerado útil para el desarrollo de la presente investigación, y también, se excluye todo el que, por el contrario, no contribuye al objetivo previamente planteado. Así mismo, se desestimaron cartas editoriales, anotaciones académicas y otros tipos de materiales bibliográficos de escaso valor cientificoacadémico o de bajo nivel de evidencia.

\section{Resultados}

Rivas (2013), en principio indicó que la acepción de Conducto Radicular debe cambiarse por el término Sistema de Conductos Radiculares, puesto que:

Al tratar de la topografía de los conductos radiculares es preciso tener presente que, de acuerdo con Hess, Meyer y Robertson, la raíz de un diente no sólo posee uno o dos conductos, sino que el conducto puede dividirse en numerosos conductos laterales y accesorios (ramificaciones).

Los conductos laterales, sin embargo, no pueden prepararse y, en el mejor de los casos, sólo pueden obturarse en parte con ciertas técnicas de obturación. Esto, no obstante, apenas menoscaba el éxito clínico, siempre que el conducto principal se prepare y obture lege artis (adecuadamente). (párr. 2-3)

En base a Cohen, este tratadista además refiriere que, generalmente, existe una estrecha relación entre una la mala prepa- ración los dientes y una mala obturación, posiblemente, debido a que se cometen errores de procedimiento tales como: pérdida de longitud, transportación del conducto, perforaciones, pérdida del sellado coronal o fractura vertical de la raíz; de los que por cierto se ha demostrado que tienen un efecto adverso sobre el sellado apical.

Aparte, facilita un par de definiciones sobre obturación radicular. Primeramente, se fundamentó en Lasala quien afirmó que el mencionado procedimiento "Es el relleno compacto y permanente del espacio vacío dejado por la pulpa cameral y radicular al ser extirpada y del propio espacio creado por el profesional durante la preparación de los conductos"; y luego, en base a Weine, dado que para este autor se trata de "...la tercera etapa del tratamiento endodóncico después del diagnóstico y la preparación de los conductos. Consiste en el aislamiento de la totalidad de la cavidad endodóncica para separar el sistema de conductos del medio bucal y del parodonto profundo". (Figura 1) 


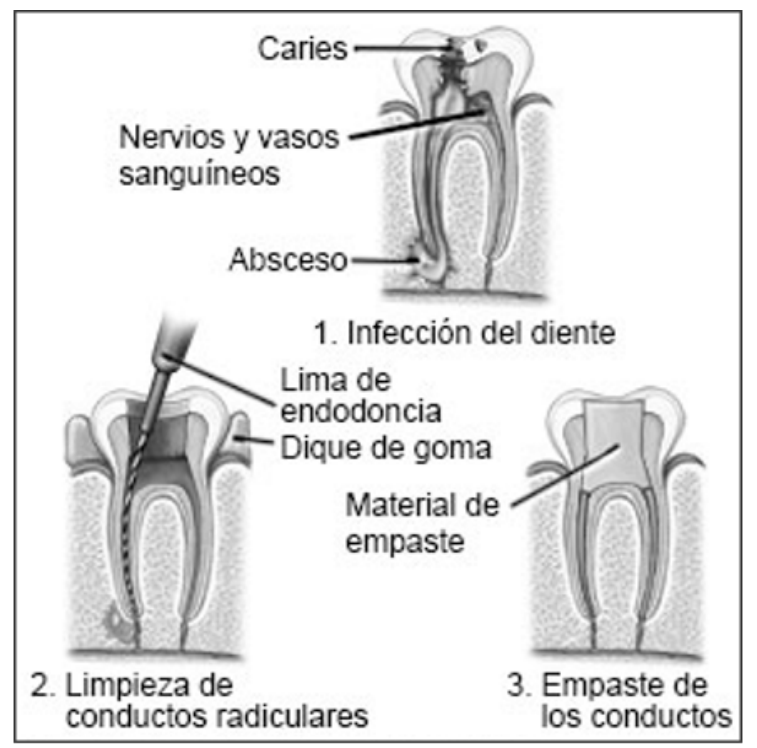

Figura 1. Origen posible del daño, tratamiento y obturación de conductos radiculares

Fuente: Tratamiento de Conducto Radicular". Drugs@ (2019)

En la figura debe comprenderse a razón de la obturación de conducto radicular, puesto que el problema ocurre con el proceso infeccioso en el diente, por lo que la preparación implica la inserción de instrumentos en los conductos radiculares, para así eliminar la pulpa afectada del diente con líquidos de limpieza (germicida). A este nivel del proceso puede ser que se tome una radiografía a fines de verificar si aún existe más pulpa que eliminar. Una vez extirpada completamente la pulpa afectada y limpiada, se procede a secar el conducto radicular para luego colocar un empaste dental dentro de la raíz del diente (pudiendo también rellenar la raíz con una pasta esteroide para aliviar cualquier inflamación en el conducto radicular), lo que en síntesis refiere la mencionada obturación. Finalmente, la pieza dental deberá ser cubierta con una corona provisoria o permanente.

Por otra parte, la Sociedad Argentina de Endodoncia había referido que "el objetivo de la obturación tridimensional es proveer un sellado adecuado a los fluidos de la totalidad del conducto radicular, para prevenir la microfiltración coronaria y apical" (Sociedad Argentina de Endodoncia, 2009, pág. 2) siendo esto porque, según explican, la causa fundamental de enfermedad pulpar y periapical son los microorganismos y sus subproductos, pero precisamente, lograr una total desinfección del sistema de conductos radiculares es un proceso difícil por demás.

El propósito de la obturación endodóntica es prevenir la reinfección de los conductos radiculares que han sido limpiados, conformados y desinfectados mediante los procedimientos de instrumentación, irrigación y medicación. Una obturación exitosa requiere del uso de materiales y técnicas capaces de rellenar de forma adecuada y homogénea el sistema de conductos radiculares para prevenir la reinfección. Esto también implica una adecuada restauración coronaria para prevenir la microfiltración bacteriana desde la cavidad oral. Ha sido demostrado que un tratamiento endodóntico es dependiente de ambas: la calidad de la obturación y la restauración final. La calidad de la obturación endodóntica es generalmente evaluada usando imágenes radiográficas. Además, durante las fases del tratamiento de preparación y obturación del conducto, el criterio clínico será muy importante para alcanzar una adecuada obturación del sistema de conductos radiculares. (Sociedad Argentina de Endodoncia, 2009, pág. 1) 


\section{La anatomía radicular}

En la obra de Cardona \& Fernández (2015) se ha encontrado un valioso aporte respecto a la trascendencia del estudio de este sistema de conductos ya que los expertos han expresado que:

La examinación radiográfica es un componente esencial en el manejo endodóntico, que apunta a aspectos de diagnóstico, planeación del tratamiento, control intraoperatorio y evaluación de los resultados. La radiografía proporciona información útil para la presencia y localización de lesiones perirradiculares, anatomía de conductos radiculares y la proximidad de estructuras anatómicas adyacentes.

La precisión de la radiografía en la evaluación de la morfología del sistema de conductos radiculares es reducida porque proporciona una imagen bidimensional de una estructura tridimensional.

En la actualidad la ayuda diagnóstica más utilizada es la Tomografía Computarizada Cone Beam (CBCT). CBCT es un avance en la imagen de tomografía computarizada; esta ha sido aplicada en evaluación periodontal; endodoncia, incluyendo evaluación de patología periapical y planeación de cirugía perirradicular; evaluación ortodóntica; y evaluación de trauma dentoalveolar.

CBCT recoge datos de volumen por medio de una rotación simple con un haz de rayos $x$ en forma de cono, y detectores de dos dimensiones, y proporciona imágenes de alta calidad diagnóstica, con tiempos cortos de exposición y bajas dosis de radiación.

CBCT es una herramienta exitosa para explorar la anatomía del conducto radicular y es precisa como la técnica de aclaramiento y tinción la cual es el Gold standard en identificar la anatomía del conducto radicular.

Las variaciones de la anatomía del sistema de conductos radiculares han sido clasificadas por varios autores. Weine y col categorizó el sistema de conductos radicula- res en cuatro tipos básicos. En otro estudio, Vertucci identificó ocho configuraciones del espacio de los conductos. Posteriormente, Sert \& Bayirli complementaron la clasificación de Vertucci. (pág. 71)

\section{Preparación de Conductos Radiculares}

Retomado el aporte de Bejarano (2014), se puede decir que esta fase previa a la obturación implica la implementación acorde de la instrumentación e Irrigación de los conductos radiculares. Respectivamente, la experta explica:

La preparación de conductos radiculares se realiza con instrumentos manuales, instrumentos accionados de forma mecánica, o mediante la combinación de ambos.

Las limas $\mathrm{K}$, de acero inoxidable, son los instrumentos más utilizados en la preparación manual de conductos radiculares. Su capacidad de corte es mayor que la de limas fabricadas en titanioaluminio y níquel-titanio (NiTi), y el tiempo de instrumentación requerido es menor. La instrumentación manual de los conductos puede realizarse mediante técnicas apicocoronales o coronoapicales; siendo ésta última de elección para lograr una mayor desinfección del sistema de conductos radiculares.

El uso de aleaciones NiTi y las modificaciones en la fabricación de los instrumentos, tales como: diferentes conicidades, y perfiles de sección, distintos ángulos de corte, profundidad de las espiras y diseño de la punta, confiere una mejora en sus propiedades, minimizando errores de procedimiento y el riesgo de fractura de los instrumentos. Esto da lugar a la aparición de numerosos sistemas para la instrumentación mecánica. Estos instrumentos, representan un nuevo enfoque para la preparación rápida de los conductos, permitiendo el uso de limas rotatorias en conductos radiculares curvos, La utilización de estos sistemas facilita su preparación, reduce el tiempo de trabajo y la fatiga del profesional y del paciente. 
Los instrumentos de NiTi trabajan, en su mayoría, por rotación horaria continua y utilizan la técnica de preparación coronoapical. En esta técnica se realiza la instrumentación del tercio coronal y medio antes de preparar la zona apical del conducto. Su objetivo es evitar interferencias de la lima en los dos tercios coronales del conducto, para acceder más libremente al tercio apical. Con ella se consigue la descontaminación progresiva del contenido radicular y se facilita su posterior obturación. No obstante, existen sistemas, como Mtwo $\AA$, que utilizan secuencialmente todos los instrumentos a longitud de trabajo, lo que se denomina "técnica de longitud simple"

Recientemente, se ha introducido el movimiento alternante, horarioantihorario, en nuevos sistemas de instrumentación para la preparación mecánica del conducto radicu-

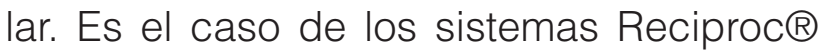
y WaveOneTM, que utilizan una única lima para la instrumentación de todo el conducto. Su movimiento alternante, reduce la fatiga cíclica del instrumento, respecto a las limas que utilizan el movimiento de rotación horaria continua. [...]
La instrumentación de conductos radiculares no elimina completamente su contenido, siendo necesaria la irrigación para la limpieza y desinfección de los mismos, sobre todo en los conductos laterales y accesorios

Los objetivos de la irrigación han sido sistematizados por diferentes autores y son:

- Disolución del tejido pulpar vital o necrótico.

- Limpieza de las paredes de los conductos para eliminar los residuos que las cubren y que taponan la entrada de los túbulos dentinarios, así como hacer fluir hacia fuera del conducto radicular los detritus formados durante la instrumentación.

- Destrucción de las bacterias y neutralización de sus productos tóxicos y componentes metabólicos.

- Lubricar los instrumentos para facilitar su paso y su capacidad de corte. (Bejarano, 2014, págs. 15-17, 23-24)

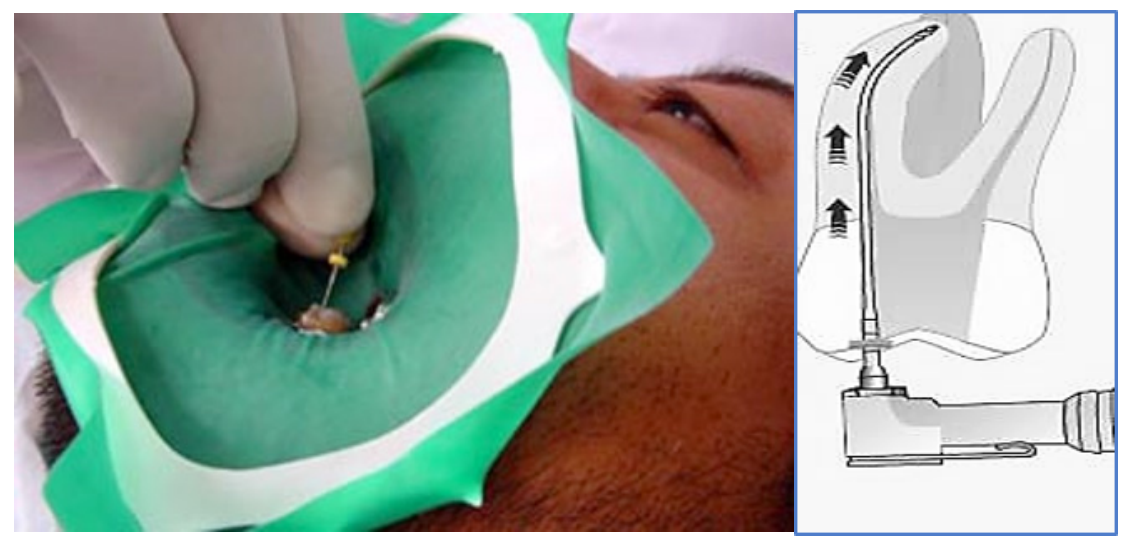

Figura 2. Algunas técnicas básicas de preparación de conductos radiculares

Fuente: Notas para el Estudio de Endodoncia" [Internet]. Rivas (2013)

\section{Materiales de Obturación del Conducto Radicular}

De Giudice \& Torres (2011) puede deducirse que, objetivamente, estos se han clasificado en: estado sólido (conos de gutapercha y plata), y en estado plástico (cementos y pastas), no obstante, agrega que pesar de que esta clasificación sea tan justa, en los procedimientos endodónticos es imprescindible alcanzar un correcto binomio entre los mencionados compuestos. Es por esto que, en la actualidad, el método de obturación más aceptado consiste en "un núcleo sólido 
o semisólido, como lo es la gutapercha, y un cemento sellador del conducto radicular". (pág. 166)

Con base en el estudio de Leonardo, M. \& Leonardo, R., estos de la misma manera aseguraron que, bastamente, la gutapercha vendría siendo el material aceptado y utilizado en la obturación de los conductos preparados, pues la evidencia, desde hace tiempo ha demostrado que, con este material, se puede alcanzar un mejor llenado del conducto, desde la porción apical hasta la corona. La gutapercha (transpoliisopreno) puede presentarse en tres formas distintas: dos formas esteáricas cristalinas $(\alpha$ y $\beta$ ) y una forma amorfa o fundida. Las tres forman parte de la obturación de conductos radiculares.

La gutapercha (transpoliisopreno) puede presentarse en tres formas distintas: dos formas steáricas cristalinas ( $\alpha$ y $\beta$ ) y una forma amorfa o fundida. Las tres forman parte de la obturación de conductos radiculares. Las puntas convencionales de gutapercha están fabricadas de fase $\beta$, que se transforma en fase $\alpha$ cuando se calienta a $42-49^{\circ} \mathrm{C}$. [...]

Sus desventajas, como la falta de rigidez y la adhesividad o la facilidad para salir del lugar al ser presionado no disminuyen las ventajas. Han buscado diversas alternativas para reemplazar a la gutapercha pero ningún otro material ha mostrado estar en condiciones de sustituirla y permanece como modelo de calidad para la obturación. (pág. 166-167)

Seguidamente indicaron que, como alternativa a la gutapercha, desde hace relativamente poco se promovió un sistema obturación a base de un tipo de resina, que en cuanto a sus propiedades físicas y técnicas de aplicación, viene siendo semejante a la gutapercha. Este material compuesto de poliuretano industrial, acondicionado para la endodoncia, se le conoce como Resilon®.
Los sistemas a base de Resilon $®$ incorporan a la resina de llenado (equivalente a la gutapercha) un cemento sellador, denominado Epiphany ${ }^{\circledR}$ (Pentron clinical technologies, Wellingford, CT, EEUU), capaz de unirse a la dentina y a la resina del núcleo (Resilon). La SybronEndo Glendora, CA, EEUU) distribuye este sistema con la denominación de RealSeal® . (pág. 167)

En la sinopsis de la obra de Ma et al. (2016) se hace referencia a una técnica de obturación diferente de la que aquí se ha dado a entender, no obstante, de éste se ha decidido destacar que, igualmente, se ha hecho referencia a materiales usados para lograr un mismo objetivo de obturación, salvar el diente.

Lo que se ha considerado trascendente de esta entrega es el hecho de que los autores han referido que, tras sus revisiones, en las que se incluyeron seis estudios (cinco hechos en Europa y uno en Asia); que en total comprendieron la evaluación de 916 participantes y 988 dientes que fueron intervenidos con obturación retrógrada mediante el uso de distintos tipos de materiales de relleno, tales como: agregado de trióxido mineral (ATM), material restaurativo intermedio (MRI), superácido etoxibenzoico (Super-EBA), composite de resina adherido a la dentina, cemento de vidrio ionomérico y amalgama, lograron determinar que "Las pruebas limitadas actuales son insuficientes para establecer conclusiones en cuanto a los beneficios de un material sobre otro",

En definitiva, de ellos es ineludible deducir, que con todo y que se han adelantado pruebas con amplias muestras poblacionales y contando con el uso de materiales de relleno de reciente tecnología, aún no es posible obtener suficiente evidencia irrefutable que facilite poder asumir un criterio de recomendación de alguno de estos tipos de aislantes como el mejor entre los disponibles. 


\section{Técnicas para la obturación del sistema de conductos radiculares}

A. Compactación lateral: un cono maestro correspondiente al calibre del tamaño final de la instrumentación y a la longitud del conducto recubierto con sellador es insertado en el conducto y es compactado lateralmente con espaciadores y rellenado con conos accesorios adicionales.

B. Compactación vertical: un cono maestro correspondiente al tamaño final de la instrumentación y de la longitud del conducto es colocado recubierto con sellador, es calentado y compactado verticalmente con atacadores, hasta que el segmento de los 3-4 mm apicales del conducto es obturado. Entonces, el remanente del conducto radicular es obturado (tercio coronario y medio) de apical a coronario usando trozos de gutapercha caliente.

C. Onda Contínua: La onda continua es esencialmente compactación vertical del material de relleno y sellador en la porción apical del conducto radicular usando dispositivos comercialmente disponibles como el System B (Sybron Endo, Orange, Calif.) y la unidad de obturación ElementsTM (Sybron Endo, Orange, Calif.) y luego realizar la obturación de la porción remanente del conducto radicular usando dispositivos de inyección como el Obtura (Obtura, Spartan, Earth City, Mo), la unidad de obturación ElementsTM (Sybron Endo, Orange, Calif.) y Hot Shot (Discus Dental, Curver City, Calif.).

D. Lateral caliente: Un cono maestro correspondiente al tamaño final de la instrumentación del conducto recubierto con sellador es insertado en el conducto, calentado con un espaciador caliente, compactado lateralmente con espaciadores y rellenado con conos accesorios adicionales. Algunos dispositivos usan vibración además del espaciador caliente.

E. Técnicas de inyección:

1. El material de relleno precalentado y termoplastizado es inyectado directamente dentro del conducto radicular. El cono maestro no es usado, pero el sellador es colocado dentro del conducto antes de la inyección. Esta técnica se realiza con los sistemas de obturación Obtura (Obtura, Spartan, Earth City, Mo), Ultrafill (Coltene Whaledent, Cuyahoga Fals, Ohio) o Calamus® (Dentsply Tulsa Dental Specialties, Tulsa, Okla).

2. Una matriz fluida, fría que es triturada, GuttaFlow ${ }^{\circledR}$ (Coltene Whaledent, Cuyahoga Fals, Ohio), consiste en gutapercha que adiciona un sellador a base de resinas, Roeko Seal. El material se presenta en cápsulas para su trituración. La técnica consiste en la inyección del material en el conducto radicular y la colocación de un solo cono maestro.

F. Termomecánica: Un cono recubierto con sellador es colocado en el conducto radicular, es enganchado con un instrumento rotatorio que por fricción lo calienta, lo plastifica y lo compacta en el interior del conducto.

\section{G. Basados en transportadores (carriers):}

1. A base de transportadores termoplastizados: La gutapercha caliente presentada en un transportador plástico es llevada directamente al conducto como obturación del mismo. Ejemplos son: Thermafil@ (Dentsply Tulsa Dental Specialties, Tulsa, Okla), RealSeal $1^{\mathrm{TM}}$ (Sybron, Orange, Calif.), Densfil ${ }^{\mathrm{TM}}$ (Dentsply Maillefer, Tulsa, Okla) y Soft-Core® (Axis Dental, Coppell, Texas).

2. A base de transportadores seccionados. Un cono de gutapercha medido y seccionado con sellador es insertado en los $4 \mathrm{~mm}$ apicales del conducto radicular. La porción remanente del conducto radicular es rellenada con gutapercha inyectable termoplastizada usando una pistola de inyección. Un ejemplo es Simpli Fill (Discus Dental, Curver City, Calif.).

H. Plastificación química: La gutapercha químicamente ablandada mediante el uso 
de solventes como el cloroformo o el eucaliptol, es insertada en el conducto, compactada lateralmente con espaciadores y el conducto rellenado con conos accesorios adicionales.

I. Conos comerciales/ solventes: Solventes como cloroformo, eucaliptol o halotano son usados para ablandar la superficie externa del cono para tomar una impresión apical del conducto. Sin embargo, debido a que ocurre contracción, el cono debe ser removido y reinsertado en el conducto con sellador y condensado lateralmente con espaciadores y conos accesorios.

J. Pastas: Las obturaciones con pastas han sido usadas en diversas aplicaciones. Cuando se las utiliza como material de obturación definitiva sin un material que ocupe el núcleo, son consideradas generalmente como menos exitosas y no ideales.
K. Barrera Apical: Las barreras apicales son importantes para la obturación de conductos de raíces inmaduras con ápices abiertos. El material de elección es el agregado trióxido mineral (MTA).

(Sociedad Argentina de Endodoncia, 2009, págs. 4-5)

Por su parte, Rangel, Luna, Téllez, \& Ley (2018), en el mismo orden de ideas refieren que, en la actualidad, las técnicas disponibles varían de acuerdo con "la dirección de compactación de la gutapercha (lateral o vertical) y la temperatura que debe aplicarse, fría o caliente (plastificada)", sin embargo, entre tantas, las técnicas pueden referirse a "condensación lateral, cono único, condensación vertical, gutapercha en frío, gutapercha termoplastificada inyectable, compactación termo-mecánica, conductores de núcleo o centro sólido envueltos en gutapercha alfa", por ejemplo. (pág. 270)

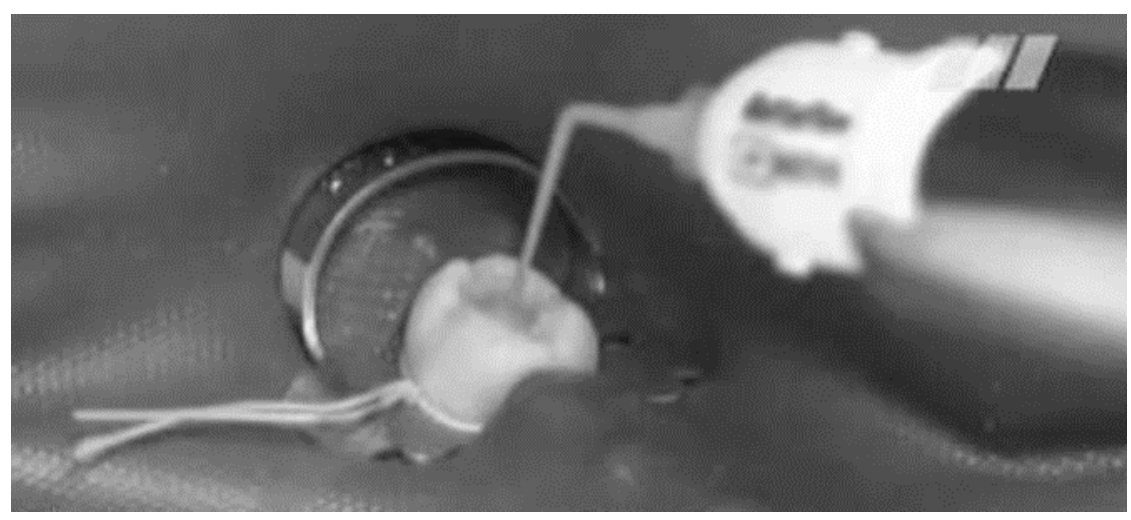

Figura 3. Ejemplo de sellado con GuttaFlow $®$

Fuente: "GuttaFlow, Sellador de conductos radiculares, Paso a Paso clínico". Coltene (2015)

Así mismo, ha sido posible percatarse que estos tratadistas, en base a sus fuentes y criterios propios, aportan una exposición más amplia respecto a las mencionadas técnicas, y de ello se considera importante destacar que:

Numerosas técnicas de obturación a base de gutapercha termo-plastificada han sido introducidas al mercado endodóncico con la finalidad de lograr un sellado hermético y tridimensional del conducto radicular en combinación con una adecuada preparación mecánica para el sellado apical con el uso de puntas de gutapercha con conicidad constante o progresiva. El papel que juega la conicidad de la gutapercha puede ser un factor a considerar en la presencia de microfiltración apical. [...]

La técnica de condensación lateral clásica es la más conocida y utilizada para obtu- 
rar los conductos radiculares y ha servido como parámetro para la evaluación de otras técnicas; en la actualidad la mayoría de las recientes técnicas de obturación ofrecen buena calidad del sellado; sin embargo, en ningún caso se ha conseguido un verdadero sellado hermético. [...]

La técnica de cono único fue una técnica de obturación muy utilizada en la década de los 50 y principios de los 60, ya que al operador ahorraba esfuerzo, tiempo y dinero. A través de los años ha sido rechazada debido a que, en los estudios de filtración, por lo general ha demostrado una capacidad de sellado inferior en comparación con técnicas que utilizan compactación adicional, y generaba una gran cantidad de fracasos reportados en un periodo muy corto, atribuidos principalmente a la filtración apical asociada a la mala instrumentación del conducto radicular y a las conicidades de las puntas de gutapercha utilizadas en ese entonces. [...]

La calidad de la obturación en la técnica de cono único puede verse comprometida con el tiempo, o la degradación podría ser más rápida cuando se utiliza un sellador relativamente más soluble en comparación con las técnicas de compactación vertical. [...]

Si bien en la actualidad ninguna asociación de materiales y técnicas ha conseguido un sellado hermético, se ha observado que las técnicas de compactación con calor se han incorporado satisfactoriamente al campo de la endodoncia debido principalmente a su buena capacidad de relleno en el interior del sistema de conductos radiculares en donde los

métodos de obturación en frío difícilmente conseguirán una obturación tridimensional, dejando esta acción a las buenas propiedades de escurrimiento de los selladores endodóncicos. (Rangel, Luna, Téllez, \& Ley, 2018, págs. 270-271)

\section{Conclusiones}

La literatura consultada básicamente ha demostrado que, comprender la anatomía del sistema de conductos radiculares (más que todo) requiere de un endodoncista verdaderamente instruido, es decir, conocedor de los detalles propios y respetuosos de elementales principios del procedimiento en sí. De allí entonces que, el especialista requiere no solamente debería saber bastamente sobre el aspecto normal de todos los tipos de cavidad pulpar, sino además de las diversidades posibles de acuerdo a variables como: la edad del paciente, las caries, la abrasión, la erosión, la enfermedad periodontal, entre otras.

Igualmente se debe comprender que, debido a que no es posible ver directamente un conducto radicular, y que solamente por medio de nuestra sensibilidad táctil es posible su percepción, se vuelve imperioso que el profesional tratante desarrolle la capacidad de imaginar con exactitud ese especial espacio endodóntico a través del estudio de la anatomía interna de los diferentes tipos de dientes, y a su vez, la perfeccione con la consecuente radiografía. Cabe resaltar que, igualmente, la literatura ha dejado ver que el examen radiográfico representa un tenue valor sugerente, debido al carácter inconcluso que, en las interpretaciones endodónticas, resulta la sumatoria de este tipo de imágenes.

Aspecto también fundamental es, el señalado por Eraso \& Muñoz (2012), quienes coincidiendo en gran medida con el criterio generalizado de otros expertos, afirman que:

La tridimensionalidad del selle apical depende de la técnica de obturación y del cemento utilizado, ya que son los dos factores que en conjunto minimizan el paso de bacterias hacia el periápice. La gutapercha es el material más utilizado y más estudiado a lo largo de la historia de la obturación de conductos, y sigue vigente debido a sus múltiples pro-piedades y su bajo costo, pese a su gran desventaja de no poseer 
propiedades adhesivas. (pág. 92)

En definitiva, podría decirse que, en gran medida, los autores coinciden en que la clave del éxito respecto a la obturación del sistema de conductos radiculares radica en la preparación de estos, que en líneas generales incluye: procedimientos de instrumentación, irrigación y medicación, a fines de que, con la obturación en sí, lo que se persigue es prevenir la microfiltración coronaria y apical, y por ende, la reinfección.

\section{Bibliografía}

Bejarano, I. (2014). Desinfección de Conductos Radiculares con Diferentes Sistema Rotatorios. Universidad de Granada, Estomatología. Granada: Editorial de la Universidad de Granada. Recuperado el 03 de 01 de 2020, de https://hera.ugr.es/ tesisugr/24146055.pdf

Cardona, J., \& Fernández, R. (2015). Anatomía radicular, una mirada desde la micro-cirugía endodóntica: Revisión. CES Odontología, 28(2), 70-99. Recuperado el 04 de 01 de 2020, de http://www. scielo.org.co/pdf/ceso/v28n2/v28n2a07.pdf

Coltene. (02 de Marzo de 2015). GuttaFlow, Sellador de conductos radiculares, Paso a Paso clínico. (Coltene Latinoamérica). Recuperado el 04 de 01 de 2020, de https://www.youtube.com/watch?v=30Q67LVok0E

Drugs. (24 de Septiembre de 2019). Tratamiento De Conducto Radicular. Recuperado el 04 de 01 de 2020, de Drugs.com: https://www.drugs.com/cg_ esp/tratamiento-de-conducto-radicular.html

Eraso, N., \& Muñoz, I. (2012). Obturación endodóntica, una visión general. Revista Nacional de Odontología, 8(15), 87-94. Recuperado el 04 de 01 de 2020, de http://198.46.134.239/index.php/od/article/view/276/286

Giudice, A., \& Torres, J. (2011). Obturación en endodoncia. Nuevos sistemas de obturación: revisión de literatura. Revista Estomatológica Herediana, 21(3), 166-174. Recuperado el 04 de 01 de 2020, de https://www.redalyc.org/pdf/4215/421539365009. pdf

Ma, X., Li, C., Jia, L., Wang, Y., Liu, W., Zhou, X., Huang, D. (17 de Diciembre de 2016). Materiales para la obturación retrógrada en el tratamiento del conducto radicular. Cochrane Base de Datos de Revisiones Sistemáticas(12). doi:10.1002/14651858. CD005517.pub2
Mejía, P., \& Bustos, K. (2012). Eficacia de la obturación ortógrada de conductos radiculares con MTA vs. MTA más conos de gutapercha. Salud Uninorte, 28(3), 391-401. Recuperado el 04 de 01 de 2020, de http://www.scielo.org.co/pdf/sun/v28n3/ v28n3a06.pdf

Rangel, O., Luna, C., Téllez, A., \& Ley, M. (2018). Obturación del sistema de conductos radiculares: Revisión de Literatura. Revista ADM, 75(5), 269-272. Recuperado el 05 de 01 de 2020, de https://www. medigraphic.com/pdfs/adm/od-2018/od185f.pdf

Rivas, R. (2013). Notas para el Estudio de Endodoncia. Notas para el estudio de Endodoncia. (X. Rivas, Ed.) Tlalnepantla de Baz, México, México. Recuperado el 03 de 01 de 2020, de https://www. iztacala.unam.mx/rrivas/obturacion.html

Sociedad Argentina de Endodoncia. (2009). Obturación del sistema de conductos rayiculares. Sociedad Argentina de Endodoncia, Seccional A.O.A. Buenos Aires: Sociedad Argentina de Endodoncia. Recuperado el 03 de 01 de 2020, de http:// www.endodoncia-sae.com.ar/download/colegas/ colegas_38.pdf

Toledo, L., Alfonso, M., \& Barreto, E. (Septiembre de 2016). Evolución del tratamiento endodóntico y factores asociados al fracaso de la terapia. Medicentro Electrónica, 20(3), 202-208. Recuperado el 03 de 01 de 2020, de http://scielo.sld.cu/pdf/mdc/ v20n3/mdc06316.pdf

Vieira, D. (21 de Marzo de 2014). Clínicas Propdental. Recuperado el 05 de 01 de 2020, de Clínicas Propdental Web Site: https://www.propdental.es/ blog/obturacion-de-los-conductos-radiculares/ 


\section{CITAR ESTE ARTICULO:}

Cedeño Delgado , M., Pinos Robalino, P., \& Segovia Palma, P. (2020). Obturación del sistema de conductos radiculares. Una revisión de la literatura. RECIAMUC, 4(1), 253-266. doi:10.26820/reciamuc/4.(1).enero.2020.253-266

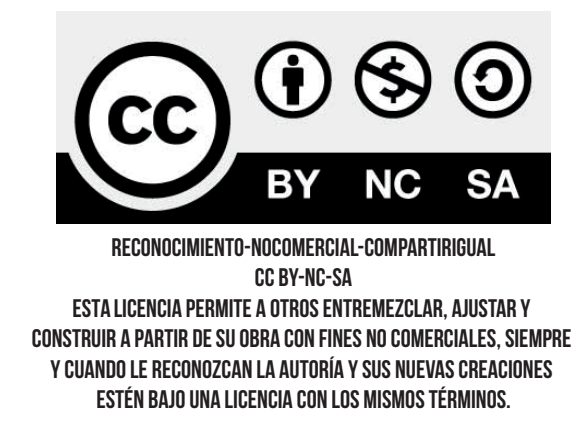

